\title{
Linear dimensional change, compressive strength and detail reproduction in type IV dental stone dried at room temperature and in a microwave oven
}

\author{
Marcos Aurélio Bomfim da SILVA', Rafael Pino VITTI' ${ }^{1}$, Simonides CONSANI ${ }^{2}$, Mário Alexandre Coelho SINHORETI ${ }^{2}$, \\ Marcelo Ferraz MESQUITA ${ }^{3}$, Rafael Leonardo Xediek CONSANI ${ }^{3}$
}

\author{
1- DDS, MSc, PhD student, Department of Restorative Dentistry, Dental Materials Division, Piracicaba Dental School, State University of Campinas, Piracicaba, \\ $\mathrm{SP}$, Brazil. \\ 2- DDS, MSc, PhD, Professor of Dental Materials, Department of Restorative Dentistry, Piracicaba Dental School, State University of Campinas, Piracicaba, \\ $\mathrm{SP}$, Brazil. \\ 3- DDS, MSc, PhD, Professor of Prosthodontics, Department of Prosthodontics and Periodontics, Piracicaba Dental School, State University of Campinas, \\ Piracicaba, SP, Brazil.
}

Corresponding address: Marcos Aurélio Bomfim da Silva - Faculdade de Odontologia de Piracicaba/UNICAMP - Av. Limeira, 901 - $13414-903$ - Piracicaba, SP - Brasil - Phone: +55-19-21065347 - Fax: +55-19-21065218 - e-mail: marcos.bomfim@fop.unicamp.br

Received: May 8, 2012 - Modification: August 22, 2012 - Accepted: September 14, 2012

\section{ABSTRACT}

$T_{\text {five }}^{\text {he }}$ he type IV dental stone is widely used for the fabrication of dyes and master casts for fixed and removable partial prostheses. It is typically normal to wait at least 24 hours for the casts to dry prior to beginning the laboratory procedures. The waiting time has been shown to be greatly reduced by using microwave drying. Objective: This study evaluated the influence of drying techniques at room temperature and microwave oven on the linear dimensional change, compressive strength and detail reproduction in type IV dental stones. Material and Methods: Three type IV dental stone brands were selected; Elite Rock, Shera Premium and Durone IV. Two different drying protocols were tested in 4 groups $(n=10)$; G1 - room temperature $\left(25 \pm 4^{\circ} \mathrm{C}\right)$ dried for 2 hours; G2 - room temperature dried for 24 hours; G3 - room temperature dried for 7 days and G4 - microwave oven dried at 800 $\mathrm{W}$ for 5 minutes and after 2 hours at room temperature. After drying, the samples were assayed for dimensional charges. The sample surface was submitted to the ImageTool 3.0 software for compressive strength in a universal testing machine with a cell load of $50 \mathrm{KN}$ at a crosshead speed of $0.5 \mathrm{~mm} /$ minutes and the detail reproduction was analyzed with a stereomicroscope at $25 x$ magnification. The statistical analysis of the linear dimensional change and compressive strength data were conducted by the ANOVA test followed by the Tukey test $(p<0.05)$. Detailed reproduction values were reported in percentages. Results: For the compressive strength test, Elite Rock and Durone IV did not present significant differences between G2 and G4, while Shera Premium did not present differences between G3 and G4. The best reproduction levels were observed for G3. Conclusions: Dental stone microwave oven drying showed a linear dimensional change similar to after room temperature drying for 24 hours and 7 days. The compressive strength of the stone dried in the microwave oven was similar to those dried at room temperature for 24 hours, with the exception of Shera Premium, which had similar results for microwave and room temperature drying for 7 days. For the microwave drying method the detail reproduction levels for samples dried at room temperature for 24 hours and 7 days were similar, except for the Durone IV.

Key words: Dental models. Compressive strength. Dental materials. Calcium sulfate. Heating. 


\section{INTRODUCTION}

Stone casts are key materials in the dental laboratory and clinical practice and must accurately reproduce the structures obtained from the impressions. To accomplish this, accuracy techniques and appropriate materials are required. The type IV dental stone is widely used to fabricate the dyes and master casts for fixed and removable partial prostheses, due to its superior mechanical properties such as compressive strength, hardness and expansion properties when compared to other dental stones ${ }^{10}$.

It is essential to obtain a strong cast with smooth and hard surface characteristics in order to allow for wax sculpting, especially at the cervical margin without cast abrasion. A hard surface is necessary for a dye stone to be resistant to abrasion, because the cavity preparation is filled with wax that is carved flush with the margins of the dye. The average dry surface Hockwell hardness of the Type IV stone is approximately 92 and for the Type III is 82. Even though the Type IV stone is harder, care should be observed when the wax pattern is being carved $^{9}$. The mechanical properties of dental stone products are related to the water/powder ratio, mixing time, mixing volume, chemical composition, relative humidity, room temperature at which the material is stored and the remaining residual water, as well as the setting time ${ }^{5}$.

Reports in the literature recommend waiting from 24 to 48 hours after the stone cast has set prior to prosthetic handling ${ }^{12}$. However, in clinical practice sometimes it is necessary to handle the casts sooner after their fabrication. These casts generally have a lower surface strength and hardness, and therefore are considered unsuitable $e^{7,10}$. The removal of all residual water in the cast by drying at room temperature is required to obtain adequate dental stone mechanical properties for the cast use. The gypsum is stable only below $40^{\circ} \mathrm{C}$ and drying at higher temperatures should be carefully managed since this may cause higher shrinkage, compressive strength reduction and promote cracks in the cast ${ }^{6}$.

Microwave radiation has been widely accepted in dentistry for the acrylic resins disinfection $2,4,12$. It has been shown that stone casts can be dehydrated in a microwave oven as an alternative drying method. This technique increased the casts' mechanical properties at room temperature ${ }^{3}$. The aim of this study was to evaluate and compare the compressive strength, dimensional stability and detail reproduction of three type IV dental stone materials following different drying techniques that employed laboratory room temperatures and microwave ovens. The null hypothesis was that microwave dehydration would not adversely affect these properties.

\section{MATERIALS AND METHODS}

Three type IV dental stones were selected: Durone IV (Dentsply, Petrópolis, Rio de Janeiro, Brazil), Elite Rock (Zhermack, Rovigo, Vêneto, Italy) and Shera Premium (Shera Werkstoff-Tecnologie, Lemforde, Niedersachsen, Germany). All materials were mixed mechanically under vacuum, following the water/powder ratio recommended by the manufacturers. The stone cast was immediately poured into the mold with the aid of a mechanical vibrator.

Two different drying protocols for linear dimensional change, compressive strength and detail reproduction tests of the stone casts were used and divided into four groups: G1 - room temperature $\left(25 \pm 4^{\circ} \mathrm{C}\right)$ dried for 2 hours; G2 room temperature dried for 24 hours; G3 - room temperature dried for 7 days and G4 - microwave oven dried at $800 \mathrm{~W}$ for 5 minutes after 2 hours at room temperature. A cup with $200 \mathrm{ml}$ of distilled water was placed in the microwave to protect the magnetron ${ }^{10}$.

\section{Linear dimensional change}

For the analysis of the linear dimensional change, forty samples were used for each stone brand and divided into four groups $(n=10)$. A metallic matrix was used with two series of seven slots with depths ranging from 0.025 to $0.300 \mathrm{~mm}$ and $2.5 \mathrm{~mm}$ of distance between the grooves, made in accordance with the specification \#25 of the American Dental Association (ADA) ${ }^{9}$. A PVC tube $30 \mathrm{~mm}$ in diameter and $15 \mathrm{~mm}$ high was placed on the metal matrix so that the slot of $0.050 \mathrm{~mm}$ deep remained in the center of the ring. The stone was weighed on an analytical balance (Sauter, model K1200, Basel, Switzerland), mixed with deionized water and measured with a test tube, in accordance to the ratio recommended by the manufacturers, and then handled mechanically by vacuum (Multivac 4, Degussa, Hanau, Hessen, Germany) with a speed of $450 \mathrm{rpm}$ for 30 seconds. After mixing, the stone was poured inside the ring previously isolated with petroleum gel, under vibration. After 2 hours, the samples were removed from the PVC tube and the surface was subjected to the scanner (HP Scanjet 2410, São Paulo, São Paulo, Brazil) with a resolution of $1200 \mathrm{dpi}$ and analyzed with the ImageTool 3.0 software. For the image calibration, the distance between lines 1 and 5 was used, comprised of a 10-mm distance between them (Figure 1).

\section{Compressive strength}

For the compressive strength test, forty samples were prepared and separated into 4 groups $(n=10)$. Specification \#25 of the $\mathrm{ADA}^{9}$ provides samples of $40 \mathrm{~mm}$ in length and $20 \mathrm{~mm}$ in diameter. However, 
in the present study metal molds were used with 20 $\mathrm{mm}$ in length and $10 \mathrm{~mm}$ in diameter, maintaining the length-diameter ratio recommended by the $\mathrm{ADA}^{9}$. The metal molds were used to obtain the dyes made by polydimethylsiloxane (Optosil Comfort, Heraeus Kulzer, Hanau, Hessen, Germany), in which the samples were made with stone. The stone was weighed on an analytical balance (Sauter, model K1200, Basel, Switzerland) and mixed with deionized water measured with a test tube, in accordance to the manufacturer's recommendations and handled mechanically by vacuum (Multivac 4, Degussa, Hanau, Hessen, Germany) with a speed of 450 rpm for 30 seconds. The silicone dyes were placed on a glass plate and filled with stone using a mechanical vibrator (Vibrator GC, MEG Chemical Co. Ltd., Shangai, China). After filling the mold, another glass plate was placed over the stone so that the ends of the sample remained flattened. The samples (Figure 2) were tested in a universal testing machine (Instron 4411 , Corona, California, USA) with a cell load of $5 \mathrm{kN}$ at a crosshead speed of $0.5 \mathrm{~mm} / \mathrm{min}$.

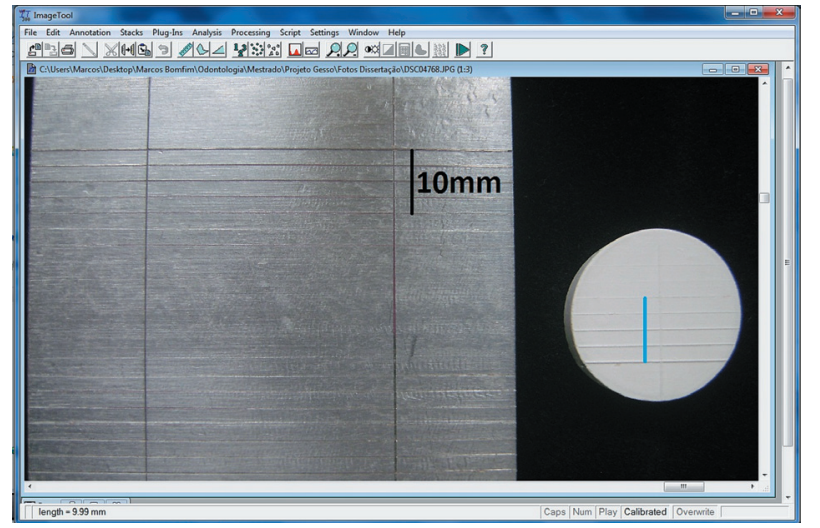

Figure 1- Sample used for software analysis of dimensional change. Black line indicates calibrated scale and blue line the measurement of the sample

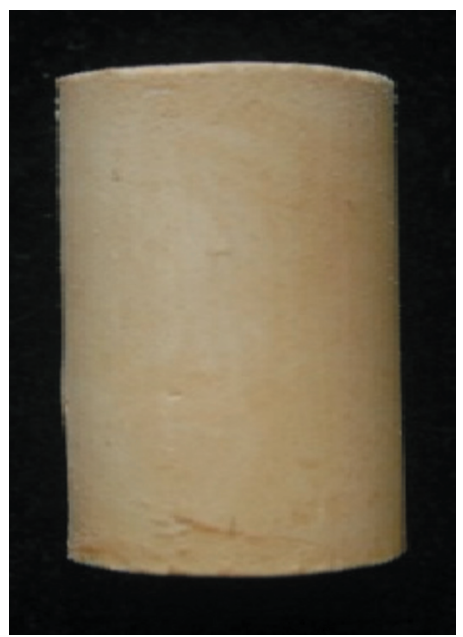

Figure 2- Sample used for compressive strength test

\section{Detail reproduction}

For the analysis of detail reproduction, forty samples were used for each stone brand, which were divided into four groups $(n=10)$. To make the samples the same metallic matrix was used as in the dimensional change test. According to the American Dental Association $(A D A)^{9}(1981)$, a detailed reproduction is considered satisfactory when a copy line of $0.050 \mathrm{~mm}$ in diameter is reproduced continuously across the stone cast.

A PVC tube was placed on the matrix $(30 \mathrm{~mm}$ diameter, $15 \mathrm{~mm}$ high), so that the groove on the metal matrix of $0.050 \mathrm{~mm}$ in depth was located in the center of the ring diameter. After mixing under vacuum, the stone was poured inside the ring previously isolated with petroleum gel, under vibration. After two hours, the samples (Figure 3) were removed from the PVC tube and the surface conditions examined with a stereomicroscope (XLT30, Nova Optical Systems, Piracicaba, São Paulo, Brazil) at 25x magnification.

\section{Statistical analysis}

The results of the linear dimensional change and compressive strength were subjected to the ANOVA followed by the Tukey test $(p<0.05)$. The values of the reproduction of details were given as a percentage.

\section{RESULTS}

The variance analysis of the linear dimensional change test showed the dental stone $(p=0.00023)$ and time $(p=0.00001)$ as significant factors, together with a stone-time interaction $(p=0.04924)$. The data are shown in Table 1.

The linear dimensional change results for the

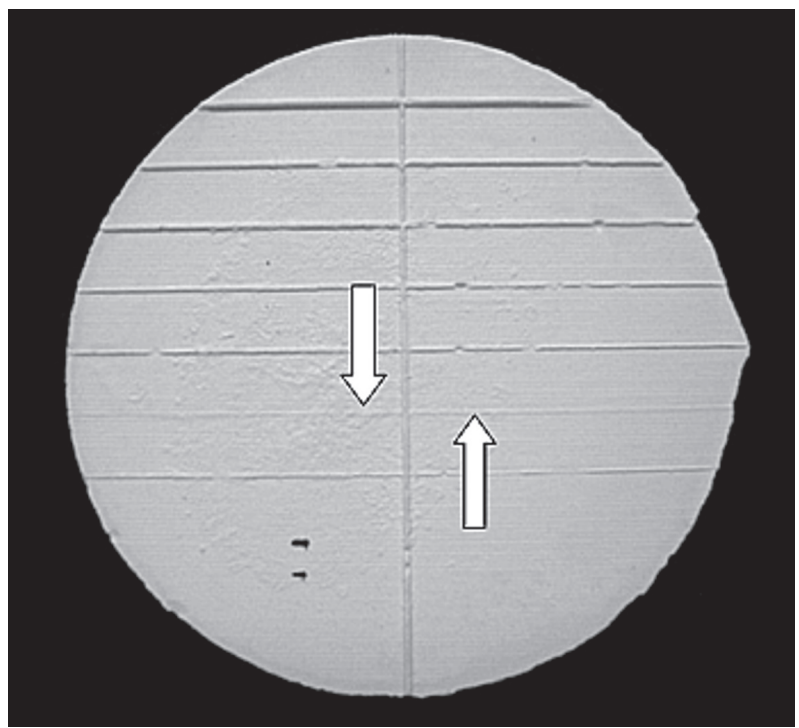

Figure 3- Graphic with the results of the details reproduction (\%) 
Table 1- Variance analysis

\begin{tabular}{ccccc}
\hline & Df & Sum of squares & Mean square & F value \\
\hline Stone & 2 & 0.00163 & 0.00081 & 10.213 \\
Time & 3 & 0.01048 & 0.00349 & 43.749 \\
Stone X Time & 6 & 0.00104 & 0.00017 & 2.18 \\
Error & 108 & 0.00862 & 0.00007 & \\
\hline
\end{tabular}

Table 2- Mean linear dimensional change $(\mathrm{mm})$, standard deviation and percentage of dimensional change as function of the drying method and stone type

\begin{tabular}{ccccc}
\hline Dental Stone & G1 & G2 & G3 & G4 \\
\hline Elite Rock & $10.034 \pm 0.007^{\mathrm{aA}}$ & $10.016 \pm 0.005^{\mathrm{bB}}$ & $10.010 \pm 0.007^{\mathrm{bB}}$ & $10.013 \pm 0.031^{\mathrm{aB}}$ \\
& $0.34 \%$ & $0.16 \%$ & $0.10 \%$ & $0.13 \%$ \\
Shera Premium & $10.032 \pm 0.007^{\mathrm{aA}}$ & $10.012 \pm 0.006^{\mathrm{bB}}$ & $10.010 \pm 0.004^{\mathrm{bB}}$ & $10.005 \pm 0.010^{\mathrm{bB}}$ \\
& $0.32 \%$ & $0.12 \%$ & $0.10 \%$ & $0.05 \%$ \\
Durone IV & $10.032 \pm 0.009^{\mathrm{aA}}$ & $10.023 \pm 0.004^{\mathrm{aB}}$ & $10.016 \pm 0.010^{\mathrm{aB}}$ & $10.015 \pm 0.007^{\mathrm{aB}}$ \\
& $0.32 \%$ & $0.23 \%$ & $0.16 \%$ & $0.15 \%$ \\
\hline
\end{tabular}

Means followed by different small letters in each column and different capital letters in each row differ statistically by Tukey test $(5 \%)$

Table 3- Variance analysis

\begin{tabular}{ccccc}
\hline & Df & Sum of squares & Mean square & F value \\
\hline Stone & 2 & 3164,17 & 1582,08 & 55,1 \\
Time & 3 & 12169,85 & 4056,61 & 141,3 \\
Stone x Time & 6 & 617,07 & 102,84 & 3,58 \\
\hline Error & 108 & 3100,45 & 28,7 & \\
\hline
\end{tabular}

Table 4 - Mean values of compressive strength (MPa) and standard deviation as function of the interaction of the drying method and stone type

\begin{tabular}{ccccc}
\hline Dental Stone & G1 & G2 & G3 & G4 \\
\hline Elite Rock & $32.18 \pm 3.2^{\mathrm{aC}}$ & $47.29 \pm 2.25^{\mathrm{aB}}$ & $61.30 \pm 1.96^{\mathrm{aA}}$ & $45.72 \pm 3.26^{\mathrm{aB}}$ \\
Shera Premium & $21.65 \pm 4.29^{\mathrm{bC}}$ & $37.70 \pm 6.32^{\mathrm{bB}}$ & $43.03 \pm 7.19^{\mathrm{bA}}$ & $43.18 \pm 5.76^{\mathrm{aA}}$ \\
Durone IV & $18.87 \pm 2.8^{\mathrm{bC}}$ & $38.16 \pm 6.30^{\mathrm{bB}}$ & $45.48 \pm 6.12^{\mathrm{bA}}$ & $34.23 \pm 4.04^{\mathrm{bB}}$ \\
\hline
\end{tabular}

Means followed by different small letters in each column and different capital letters in each row differ statistically by Tukey test $(5 \%)$

drying method are illustrated in Table 2. For the Elite Rock, G1 showed the highest level of dimensional expansion, which was statistically higher than the other groups. For G2, G3 and G4, Elite Rock did not show statistically significant differences. G1 demonstrated no significant differences. For $\mathrm{G} 2$ and G3, Durone IV had the highest levels of expansion and for G4, Shera Premium presented the lowest expansion.

Variance analysis of the compressive strength test showed that the stone $(p=0.00001)$ and time $(p=0.00001)$ were significant factors and that there is a stone-time interaction $(p=0.00314)$. The data are shown in Table 3.

Table 4 shows the compressive strength values for the different drying methods. G1 with Elite Rock presented the lowest values of compressive strength. G2 and G4 did not show statistically significant differences. G3 showed significantly higher compressive strength values than G1, G2 and G4. Stone Shera Premium had the highest strength in $\mathrm{G} 3$ and G4, with no statistical difference 
between these groups. Lower strength values are found in $\mathrm{G} 1$ and intermediate values in $\mathrm{G} 2$. The Durone IV stone showed the highest compressive strength values in $\mathrm{G} 3$ and the lowest values in G1. No statistically significant differences were found between G4 and G2. When the cast brands were compared, Elite Rock showed the highest compressive strengths for G1, G2 and G3. For G4, the Durone IV stone had the lowest compressive strength values.

The test results for detail reproduction according to the drying method used are shown in Figure 3 as percentages. Detail reproduction can be considered satisfactory when the cast maintains the continuous $0.050 \mathrm{~mm}$ line of the matrix. After reviewing the reproductions with a stereomicroscope, the G1 drying method presented the worst rates of reproduction for each cast. The highest reproduction values were found for G3.

\section{DISCUSSION}

This study was conducted to verify that the type IV dental stone drying in a microwave oven to save time would not have a negative influence on the linear dimensional change, compressive strength and detail reproduction of some commercial dental stones. The results showed that the three brands of type IV dental stones were affected differently by the drying methods. The null hypothesis that these properties would not be negatively influenced by the microwave dehydration was accepted.

The setting expansion of the dental stones is an important factor for many dental applications. The casts must have slightly larger dimensions than the buccal structures to offset the impression material shrinkage and then ensure that the dental pieces are adequately manufactured. The dental stone expansion due to the calcium sulfate hydration during the mix promotes the crystallization reaction where crystal growth occurs from the crystallization nucleus, providing volumetric expansion that can range from 0.06 to $0.5 \%{ }^{1}$.

ADA Specification \#25 recommends a setting expansion of type IV dental stone up to $0.1 \%$ at 2 hours after the mix. Another important fact to be considered is that the setting expansion is inherent to the crystallization of the stone and occurs according to the calcination process of the dental stone used to obtain the hemihydrates ${ }^{9,10,15}$.

The setting expansions obtained in this study for the samples subjected to drying at room temperature and in a microwave oven for three different brands of dental stone were higher than the values advertised on the product labels. The three brands showed no statistically significant difference between expansion levels for G2, G3 and G4, while the highest expansion values were found in G1 (Table 2). The difference between the expansion mentioned by the manufacturer and those obtained in this study could be due to the environmental conditions of the laboratory, where the samples were prepared in a room with no temperature and humidity control, purposely to establish an environmental similarity to the clinical or prosthetic laboratory conditions.

The strength of gypsum-based products is usually expressed in terms of compressive strength, which is directly related to the material's ability to fracture resistance when subjected to compressive tensions. This mechanical property is linked to other important cast properties, especially hardness and wear strength. Thus, the dental stone compressive strength is an important factor in the rehabilitation work in dentistry.

The compressive strength values found for the different drying techniques (Table 4) indicate that the casts dehydrated in a microwave oven at 2 hours (G4) after mixing showed average values of compressive strength with no statistical differences when compared with those dried at room temperature for 7 days (G3, Shera Premium) and with no statistical difference from samples dried at room temperature for 24 hours (G2) for Elite Rock and Durone IV. Similar results were found in the study by Tuncer, et al. ${ }^{14}$ (1993), who evaluated drying techniques that employed a microwave oven and conventional oven during the times of 2, 4, 24 and 48 hours. However, the data were different from those found by Leubke and Schneider ${ }^{8}$ (1985) who evaluated eight brands of type IV dental stones dried in a microwave oven with $1450 \mathrm{~W}$ for 5 minutes. These authors found no statistically significant differences between the compressive strength values for the samples dried in a microwave oven and at room temperature, considering that this result may have been influenced by the use of high-power microwaves. The samples dried in a microwave oven and at room temperature for 24 hours and 7 days demonstrated statistically similar compressive strength values, suggesting that the casts could be used for prosthetic processing two hours after impression pouring.

Hersek, et al. ${ }^{6}$ (2002) analyzed the diametral tensile strength of casts that were dried in a microwave oven at 10 minutes after the initial setting and concluded that drying increased the dental stone strength by quick water evaporation that remains in the mass, due to the heat produced by the microwave radiation. Times between 10 and 60 minutes before drying in the microwave oven were also tested in this study to observe the dental stone dehydration. For these times, casts dried in a microwave oven showed low compression strength, fracturing easily with little charge, justifying the two-hour time chosen before microwave drying 
samples for the compressive strength test.

The detail reproduction quality of stone casts can be influenced by the size and regularity of the calcium sulfate a-hemihydrate particles. The Elite Rock and Shera Premium brands proved to be consistently less viscous when compared with the Durone IV, that may have influenced the material flow on the metal matrix, allowing the easier penetration of the dental stone and consequently better reproduction of the $0.050 \mathrm{~mm}$ line.

Due to the absence of further research in the literature about the detail reproduction in casts that are dried in a microwave oven, it is not possible to establish parameters for comparison with the results of this study. However, the results of the dimensional change and compressive strength were consistent with the few studies reported in the literature, also demonstrating the influence of microwave oven drying on the dehydration of type IV dental stones $6,8,14,16$. The comparison of the dimensional change and compressive strength results of the brands cannot be discussed since the manufacturers did not provide the complete chemical composition of their products.

However, the results of this study supported that the microwave drying method can be used without causing deleterious effects on the linear dimensional, compression strength and detail reproduction in the casts of type IV dental stones when compared to material drying at room temperature.

The limitations of this in vitro study includes the fact that there was no information in relation to the clinical conditions that an indirect restoration should present when manufactured in cast dried by the microwave procedure. This fact should be a topic for further investigations.

\section{CONCLUSION}

It was concluded that: dental stone microwave oven drying showed a linear dimensional change similar to after room temperature drying for 24 hours and 7 days. The compressive strength of a stone dried in a microwave oven was similar to those dried at room temperature for 24 hours, with the exception of Shera Premium, with similar results for microwave and room temperature drying for 7 days. For the microwave drying method, the detail reproduction levels for the samples dried at room temperature for 24 hours and 7 days were similar, except for the Durone IV.

\section{REFERENCES}

1- Anusavice KJ, Phillips' science of dental materials. $11^{\text {th }}$ ed. Philadelphia: Elsevier; 2003. p. 275.

2- Berg E, Nielsen $\varnothing$, Skaug N. Efficiency of high-level microwave disinfection of dental gypsum casts: the effects of number and weight of casts. Int J Prosthodont. 2007;20:463-4.

3- Canay S, Hersek N, Çiftçi Y, Akça K. Comparison of diametral tensile strength of microwave and oven-dried investment materials. J Prosthet Dent. 1999;82:286-90.

4- Consani RL, Azevedo DD, Mesquita MF, Mendes WB, Saquy PC. Effect of repeated disinfections by microwave energy on the physical and mechanical properties of denture base acrylic resins. Braz Dent J. 2009;20:132-7.

5- Craig RG. Restorative dental materials. St. Louis: Mosby; 1997. p. 333-7.

6- Hersek N, Canay S, Akça K, Ciftçi Y. Tensile strength of type IV dental stones dried in a microwave oven. J Prosthet Dent. 2002;87:499-502.

7- Luebke RJ, Chan KC. Effect of microwave oven drying on surface hardness of dental gypsum products. J Prosthet Dent. 1985;54:431-5.

8- Luebke RJ, Schneider RL. Microwave oven drying of artificial stone. J Prosthet Dent. 1985;53:261-5.

9- New American Dental Association Specification No. 25 for dental gypsum products. J Am Dent Assoc. 1972;84:640-4.

10- O 'Brien WJ. Gypsum products. In: __. Dental materials and their selection. Illinois: Quintessence; 1997. p.51-77.

11- Ragain JC, Grosko ML, Raj M, Ryan TN, Johnston WM. Detail reproduction, contact angles, and die hardness of elastomeric impression and gypsum die material combinations. Int J Prosthodont. 2000;13:214-20.

12- Rohrer MD, Bulard RA. Microwave sterilization. J Am Dent Assoc. $1985 ; 110: 194-8$.

13- Schwedhelm ER, Lepe X. Fracture strength of type IV and type $\mathrm{V}$ die stone as a function of time. J Prosthet Dent. 1997; 78:554-9. 14- Tuncer N, Tufekçioglu HB, Calikkocaoglu S. Investigation on the compressive strength of several gypsum products dried by microwave oven with different programs. J Prosthet Dent. 1993;69:333-9.

15- Winkler MM, Monaghan P, Gilbert JL, Lautenschlager EP. Freeze-drying and scanning electron microscopy of setting dental gypsum. Dent Mater. 1995;11:226-30.

16- Yap AU, Yap SH, Teo JC, Tay CM, Ng KL, Thean HP. Microwave drying of high strength dental stone: effects on dimensional accuracy. Oper Dent. 2003;28:193-9. 